\title{
THE EFFECTS OF LEARNING STYLES OF PRE-SERVICE TEACHERS ON THEIR SKILLS TO PREPARE SKETCHNOTES
}

\author{
Nilgün Tatar, \& Meral Șeker \\ Faculty of Education, Alanya Alaaddin Keykubat University (Turkey)
}

\begin{abstract}
The study aims to explore the effects of learning styles of pre-service teachers on the level of their skills to create sketchnotes. In order to collect the data regarding the participants' dominating visual and verbal learning styles, the questionnaire "Dominating Visual or Verbal Learning Style of Learners" was applied to 44 prospective teachers at the faculty of education in a public university. The participants also created sketchnotes on a given topic. The findings indicate that the sketchnotes prepared by the participants with dominating visual learning style included more colours, highlights and other visual elements while the participants with dominating verbal learning style used more texts in their sketchnotes. The findings, thus, suggest that there can be a correlation between learning styles and note-taking skills of learners.
\end{abstract}

Keywords: Learning style, sketchnote, pre-service teachers.

\section{Introduction}

Individuals differ in the style they use for learning. Having the suitable learning style enables the individual to learn more easily and effectively, and thus, learning style is the key to learn. According to Dunn and Dunn (1993), learning style is the process that starts when the learner tries to concentrate on new and challenging information and that continues as the learner processes and internalizes it. The concept of learning style started to be used in the field of education in 1970s. Studies since then have frequently indicated that learning styles are among the important components of learning process (Günaydın, 2011). Learners use their five senses in order to reach information in a given learning situation and they become visually, audially, and kinesthetically active. Visual learners use their visual senses more effectively while audial learners benefit more from their audial senses. Knesthetic learners, on the other hand, learn better by touching or being physically active. Learners usually use these three senses simultaneously, however, one of these three senses may have a dominating role in each learner's learning process (Felder \& Silverman, 1988).

Learning materials assist learners to learn faster and in an easier way. The interaction between learners and learning materials occurs though the language of visual designs in the materials. Words and images are directed this language. Words form texts and headings while visuals refer to pictures, designs and photos included to add simple or abstract meanings. Another type of learning material is the one composed of words and images. Whatever elements are used in these materials all compose the learning elements in harmony (Alpan, 2008).

Visual materials are crucial in visual learning. As teaching materials, pictures, graphs, tables, or drawings can facilitate learning as they enable learners to visualize abstract concepts and internalize them more easily. Visuals also help learners to understand relationships between concepts while increasing their attention and enriching the learning process. Visuals are convenient teaching tools as they are not only easy to use and integrate into any learning material and subject, but are available almost cost-free as well.

Visuals in teaching have been widely used since the use of pictures, graphs or diagrams enrich the materials visually. They enable concepts to be more easily understood and evaluated. They also help learners to pay attention and to make connections among concepts. Pictures are used to transfer abstract concepts through realistic visuals. Graphs on the other hand, are useful in transmitting knowledge with statistics or describing it socially while they help learners to more cognitively beyond conceptualizing. Diagrams are important in summaries. Especially they are effective when summaries of the topic. Pictures, graphs and diagrams are cost efficient and can be easily (Yanpar, 1999). These are teaching tools that could easily be used in teaching any subject or topic. 
Sketchnotes are the notes that consist text and visuals such as drawings, pictures, objects, frames, letters, or numbers. They can be used to take notes of the learning materials, summarize, brainstorm, or to prepare a plan for any learning task. They help to visualize the learning material and thus, make learning easier and more retentive. By making lessons more enjoyable, sketchnotes can also increase learner participation and concentration as well as encouraging creative thinking.

As sketchnotes consist of visual and written elements they are thought to correlate with learning styles. Thus, determining how sketchnotes are affected by learners learning styles could enable better planning for lesson materials, assignment tasks, or other instructional activities. In this respect, the study aims to explore the effects of learning styles of pre-service teachers on the level of their skills to create sketchnotes.

\section{Method}

The study was designed following convergent parallel design. In order to gather in-depth data, qualitative and quantitative data were collected simultaneously. The findings are presented in combination of both qualitative and quantitative data.

\subsection{Participants}

The sample consisted 44 prospective teachers at a faculty of education department at a state university. They were all third graders with 37 of them female and 7 male students.

\subsection{Data tools}

The data was collected using a Likert-type questionnaire and sketchnotes. In order to collect the data regarding the participants' dominating visual and verbal learning styles, the questionnaire "Dominating Visual or Verbal Learning Style of Learners" developed by Childers, Houston and Heckler (1985) was used. The scale included 16 items, eight of which were related to visual and 8 to verbal learning style.

The participants were also requested to prepare a sketchnote in any topic they wanted in Science. They were informed about preparing sketchnotes and possible materials they could use along with some sample sketchnotes. Then, they were allocated a week to prepare their sketchnotes.

\subsection{Data analysis}

The responses of the participants were analyzed statistically using SPSS 16.0 program. Since the data was not normally distributed, non-parametric analyses were conducted. The scores that students received from sketchnotes were analyzed descriptively using a rubric prepared by the researcher. The scores they received from visual and verbal learning styles were analyzed separately. Finally, the scores from the sketchnotes and the scores from the learning styles questionnaire were compared.

\section{Results}

The dominant learning styles of the participants based on gender variable are displayed in Table 1. The dominant style among the participants is visual with $5(\% 14)$ for females and $2(\% 29)$ for males. For $3(\% 8)$ female students, both visual and verbal styles were at the same rate whereas none of the male students showed such a similar rate.

Table 1. Dominant learning style of the participants based on gender.

\begin{tabular}{|lccccc|} 
& Female & & Male & & Total \\
& $\mathrm{n}$ & $\%$ & $\mathrm{n}$ & $\%$ & $\mathrm{n}$ \\
Visual & 29 & 78 & 5 & 71 & 34 \\
Verbal & 5 & 14 & 2 & 29 & 7 \\
Visual-Verbal & 3 & 8 & - & - & 3 \\
Total & 37 & 100 & 7 & 100 & 44 \\
\hline
\end{tabular}

The results of the sketchnotes prepared by the participants are presented in Table 2 . The participants' use of sketchnotes based on their learning style was analyzed. It was found that all the participants paid attention to headings and shapes in their sketchnotes. 
Table 2. The distribution of visual and verbal elements in sketchnotes.

\begin{tabular}{|c|c|c|c|c|c|c|c|c|c|c|c|}
\hline \multicolumn{4}{|c|}{ Visual } & \multicolumn{4}{|c|}{ Verbal } & \multicolumn{4}{|c|}{ Visual-Verbal } \\
\hline Visual & & Verbal & & Visual & & Verbal & & Visual & & Verbal & \\
\hline Shape & 34 & $\begin{array}{l}\text { Information } \\
\text { Box }\end{array}$ & 3 & Shape & 7 & $\begin{array}{l}\text { Information } \\
\text { Box }\end{array}$ & 5 & Shape & 3 & $\begin{array}{l}\text { Information } \\
\text { Box }\end{array}$ & 2 \\
\hline Diagram & 6 & $\begin{array}{l}\text { Written } \\
\text { Explanation }\end{array}$ & 33 & Diagram & 2 & $\begin{array}{l}\text { Written } \\
\text { Explanation }\end{array}$ & 7 & Diagram & 2 & $\begin{array}{l}\text { Written } \\
\text { Explanation }\end{array}$ & 3 \\
\hline Model & 8 & Heading & 34 & Model & - & Heading & 7 & Model & 2 & Heading & 3 \\
\hline Table & 3 & Sub-heading & 18 & Table & - & Sub-heading & 6 & Table & 1 & Sub-heading & 2 \\
\hline Graph & 6 & Ordering & 4 & Graph & - & Ordering & 3 & Graph & 3 & Ordering & 2 \\
\hline Picture & 1 & $\begin{array}{l}\text { Classificatio } \\
\mathrm{n}\end{array}$ & 30 & Picture & - & Classification & 6 & Picture & - & Classification & 2 \\
\hline Symbol & 9 & & & Symbol & 2 & & & Symbol & 2 & & \\
\hline Arrow & 25 & & & Arrow & 1 & & & Arrow & - & & \\
\hline Coloring & 34 & & & Coloring & 4 & & & Coloring & 1 & & \\
\hline $\begin{array}{l}\text { Highlighti } \\
\text { ng }\end{array}$ & 34 & & & $\begin{array}{l}\text { Highlightin } \\
\mathrm{g}\end{array}$ & 6 & & & $\begin{array}{l}\text { Highlightin } \\
\mathrm{g}\end{array}$ & 3 & & \\
\hline
\end{tabular}

While visual learners tend to use more frequent graphs and tables in addition to coloring and highlighting, verbal learners are more likely to use information boxes and classifications for explaining concepts. Visual-verbal learners, on the other hand, balance between visual and written elements in their sketchnotes. The participants' use of visual and written elements were also analyzed based on gender variable (Table 3).

Table 3. The distribution of visual and written elements in sketchnotes based on gender.

\begin{tabular}{|c|c|c|c|c|c|c|c|}
\hline \multicolumn{3}{|c|}{ Female } & \multicolumn{5}{|c|}{ Male } \\
\hline \multicolumn{2}{|l|}{ Visual } & \multicolumn{2}{|l|}{ Verbal } & \multicolumn{2}{|l|}{ Visual } & \multicolumn{2}{|l|}{ Verbal } \\
\hline Shape & 37 & Information Box & 10 & Shape & 7 & Information Box & - \\
\hline Diagram & 10 & $\begin{array}{l}\text { Written } \\
\text { Explanation }\end{array}$ & 36 & Diagram & - & Written Explanation & 7 \\
\hline Model & 8 & Heading & 37 & Model & 2 & Heading & 7 \\
\hline Table & 4 & Sub-heading & 21 & Table & - & Sub-heading & 5 \\
\hline Graph & 8 & Ordering & 7 & Graph & 1 & Ordering & 2 \\
\hline Picture & 1 & Classification & 33 & Picture & - & Classification & 5 \\
\hline Symbol & 11 & & & Symbol & 2 & & \\
\hline Arrow & 21 & & & Arrow & 5 & & \\
\hline Coloring & 34 & & & Coloring & 5 & & \\
\hline Highlighting & 36 & & & Highlighting & 7 & & \\
\hline
\end{tabular}

The use of visual and written elements in the sketchnotes were analyzed based on gender. The results indicate that female participants tend to use visuals such as diagrams, tables, pictures and written elements like information boxes more frequently than the male participants. The males, on the other hand, used sub-headings in their texts and classifications in their explanations. The impacts of the participants' learning styles on their use of visuals are displayed in Table 4.

Table 4. The differences in the scores received from the visuals in the sketchnotes based on learning styles.

\begin{tabular}{|lccccc|}
\hline Learning Style & $\mathrm{n}$ & Mean Rank & $\mathrm{df}$ & $\mathrm{x}^{2}$ & $\mathrm{p}$ \\
Visual & 33 & 26,47 & 2 & 17,927 &, 00 \\
Verbal & 7 & 4,64 & & & \\
Visual-Verbal & 44 & 21,00 & & & \\
\hline
\end{tabular}

The visual elements used in the participants sketchnotes were analysed based on their learning styles. According to the results from Kruskal Wallis H-Test independent samples test, there is a significant difference in the use of visual elements based on the participants learning styles $\left(\mathrm{x}^{2}(2)=17,92\right.$, $\mathrm{p}<.05)$. The reason for the difference was analysed using Mann Whitney U-Test for independent samples. The results show that there is a significant difference in terms of visual element use between the participants with visual learning style and the ones with verbal style $(U=3,5, p<.05)$. The participants with visual-verbal learning style use visual elements more frequently than verbal style learners $(U=1,00$, $\mathrm{p}<.05)$. The effect of the participants' learning style on their use of written elements in their sketchnotes are presented in Table 5. 
Table 5. The difference between sketchnote scores of the participants based on their learning styles.

\begin{tabular}{|lccccc|}
\hline Learning Style & $\mathrm{n}$ & Mean Rank & $\mathrm{df}$ & $\mathrm{x}^{2}$ & $\mathrm{p}$ \\
Visual & 33 & 17,56 & 2 & 21,080 &, 00 \\
Verbal & 7 & 38,50 & & & \\
Visual-Verbal & 44 & 35,25 & & & \\
\hline
\end{tabular}

The verbal elements in the participants' sketchnotes were analysed using Kruskal Wallis H-Test independent samples test. There is a significant difference in the use of written elements based on learning styles $\left(\mathrm{x}^{2}(2)=21,08, \mathrm{p}<.05\right)$. The reason for the difference between the groups were investigated using Mann Whitney U-Test for independent samples. Accordingly, a significant difference was found in terms of written element use between the participants with verbal learning style and the ones with visual style $(\mathrm{U}=6,0, \mathrm{p}<.05)$. The participants with both verbal and visual learning styles were found to use written elements more frequently than the participants with visual learning style (U=12,50, $p<.05)$.

\section{Discussion}

Learners use their learning styles actively while accessing, understanding and processing information. While some learners respond better to diagrams, graphs and pictures; others learn better with verbal or written explanations. Most of the learners are visual learners. However, the majority of the classroom instruction is carried out verbally. This shows that many learners cannot benefit from the lessons instructed verbally. Those who learn effectively are the ones that can process information both visually and verbally (Felder, 1993). In learning situations where knowledge is transferred both verbally and visually, all learners learn more effectively.

The findings indicate that the majority of the participants are visual learners. It is also revealed that the participants' learning styles influence their use of verbal and visual elements in their sketchnotes. The learners with visual learning styles used more visual elements in the sketchnotes they prepared while verbal learners used verbal elements more. The ones with both learning styles used verbal and visual elements together.

Fleming (2001) offers extensive suggestions for classroom approaches for matching teaching styles and learning styles. When teaching materials include both visual and verbal elements, they will be more meaningful for learners with visual and verbal learning styles while enabling retention. Furthermore, the visual and verbal elements in learners' notes will enhance processing knowledge and help them learn faster. Based on the findings of this study, it is suggested that teachers inform learners about and guide them to use sketchnotes with verbal and visual elements.

\section{References}

Alpan, G. (2008). Visual literacy and instructional technology. Yüzüncü Yll University Journal of Education. V (II), 74-102.

Childers, T. L., Houston, M. J., \& Heckler, S. E., (1985). Measurement of individual differences in visual versus verbal information process. Journal of Consumer Research, 12, 125-134.

Dunn R, \& Dunn K. (1993). Teaching Elementary Students Through Their Individual Learning Styles: Practical Approach for Grades 3-6. Massachusetts, USA: Pearson.

Felder, R. M., \& Silverman L. (1988). Learning and teaching styles in engineering education. Engineering Education, 78 (7), 674-681.

Felder, R. M. (1993). Reaching the second tier: Learning and teaching styles in college science education. College Science Teaching, 23(5), 286 - 290.

Fleming, N. D. (2001). Teaching and learning styles: VARK strategies. Christchurch, New Zealand: N.D. Fleming.

Günaydın, F. (2011). The investigation of the relationship between the learning styles and the study habits of the $4^{\text {th }}$ and $5^{\text {th }}$ grade primary school students (Illkögretim 4. ve 5. slnuf ögrencilerinin öğrenme stilleri ile ders çalışma alışkanlıkları arasındaki ilişsinin incelenmesi). Marmara University, Educational Sciences Institute, Unpublished Master Thesis, İstanbul, Turkey.

Yanpar, T. (1999). Instructional Technologies and Material Design (Öğretim Teknolojileri ve Materyal Tasarımı). Ankara, Turkey: Anı Yayıncılık. 